\title{
MANEJO DE COLHEITA E ESPAÇAMENTO DA PALMA-FORRAGEIRA, EM CONSÓRCIO COM SORGO GRANÍFERO, NO AGRESTE DE PERNAMBUCO ${ }^{1}$
}

\author{
IDERVAL FARIAS ${ }^{2}$, MÁRIO DE ANDRADE LIRA 3 , DJALMA CORDEIRO DOS SANTOS ${ }^{4}$, \\ JOSÉ JORGE TAVARES FILHO ${ }^{4}$, MÉRCIA VIRGINIA FERREIRA DOS SANTOS ${ }^{5}$, \\ ANTÔNIO DE PÁDUA MARANHÃO FERNANDES ${ }^{5}$ e VENÉSIO FELIPE DOS SANTOS ${ }^{4}$
}

\begin{abstract}
RESUMO - Este trabalho foi realizado na zona semi-árida de Pernambuco e teve como objetivo investigar o efeito de espaçamento, e a freqüência e intensidade de colheitas da palma-forrageira (Opuntia ficus-indica Mill.) consorciada com sorgo granífero (Sorghum bicolor (L.) Moench). O delineamento experimental foi o de blocos ao acaso em parcelas subdivididas, sendo os espaçamentos alocados nas parcelas principais, e as freqüências e intensidades de colheitas, nas subparcelas. Os resultados são de um período de 12 anos, e as produções de matéria seca de palma, de grãos e restolhos de sorgo foram: $5,23,1,65$ e 2,$07 ; 4,51,1,30$ e 2,$10 ; 2,75,1,97$ e $3,51 \mathrm{t} / \mathrm{ha} /$ ano, em espaçamentos de $2,0 \mathrm{~m} \mathrm{x}$ $1,0 \mathrm{~m} ; 3,0 \mathrm{~m} \times 1,0 \mathrm{~m} \times 0,50 \mathrm{~m}$ e 7,0 $\mathrm{m} \times 1,0 \mathrm{~m} \times 0,50 \mathrm{~m}$, respectivamente. A produção de matéria seca foi diferente entre as freqüências de corte, quando foram conservados os artículos primários: $4,08 \mathrm{t} / \mathrm{ha}$ /ano na freqüência de quatro anos, e de 3,43 t/ha/ano na freqüência de dois anos. A produção de palma aumentou com o período de crescimento da planta, nas duas intensidades de corte estudadas. A composição química dos artículos de palma e dos restolhos de sorgo foi pouco afetada pelos tratamentos.
\end{abstract}

Termos para indexação: cactus-forrageiro, consorciação, densidade de plantio, freqüência de corte, intensidade de corte, Opuntia ficus-indica, Semi-Árido.

\section{HARVEST MANAGING AND PLANT SPACING OF SPINELLES FODDER CACTUS, UNDER GRAIN SORGHUM INTERCROPPING AT THE SEMI-ARID REGION OF PERNAMBUCO STATE, BRAZIL}

\begin{abstract}
This trial was carried out in the semi-arid region of Pernambuco, aiming to study plant spacing and harvest frequencies and intensities of forage cactus (Opuntia ficus-indica Mill.). An experimental design in a split plot design was applied, in which plant spacing were used as the main plots and harvest frequencies and intensities as the subplots. Results presented in this work are related to a twelve-year period. The dry matter yields of forage cactus, sorghum grains and stover were: $5.23,1.65$ and $2.07 ; 4.51,1.30$ and $2.10 ; 2.75,1.97$ and 3.5 ton/ha/year, for plant spacing $2.0 \mathrm{~m} \mathrm{x} 1.0 \mathrm{~m} ; 3.0 \mathrm{~m} \mathrm{x}$ $1.0 \mathrm{~m} \times 0.50 \mathrm{~m}$ and $7.0 \mathrm{~m} \times 1.0 \mathrm{~m} \times 0.50 \mathrm{~m}$, respectively. Dry matter yield was different between harvest frequencies, when primary articles were conserved: 4.08 ton/ha/year under a four-year cutting frequency and 3.43 ton/ha/year under a two-year frequency. Yield increased with plant growth period, in both cutting intensities. Chemical contents of cactus forage and sorghum stover were little affected by treatments.
\end{abstract}

Index terms: Opuntia ficus-indica, plant density, cutting frequency, cutting intensity.

\footnotetext{
${ }^{1}$ Aceito para publicação em 17 de maio de 1999.

${ }^{2}$ Eng. Agrôn., M.Sc., Secretaria de Agricultura, IPA. Av. Gal. San Martin, 1371, Bongi, CEP 50761-000 Recife, PE. E-mail:val@hotlink.com.br

${ }^{3}$ Eng. Agrôn., Ph.D., Secretaria de Agricultura, IPA. Bolsista do CNPq. E-mail: mlira@hotlink.com.br

${ }^{4}$ Eng. Agrôn., M.Sc., IPA.

${ }^{5}$ Zootecnista, M.Sc., Universidade Federal Rural de Pernambuco, Av. Manoel de Medeiros S/N, Dois Irmãos, CEP 52171-030 Recife, PE. Acordo IPA/UFRPE.
}

\section{INTRODUÇÃO}

A pecuária de Pernambuco concentra-se nas zonas do Agreste e Sertão; na primeira, encontra-se a tradicional Bacia Leiteira do Estado. Em ambas as áreas, ocorre o fenômeno natural da seca, que tem causado grandes prejuízos aos criadores, e problemas socioeconômicos ao Estado, em decorrência da perda de peso, queda na produção de leite, e morte 
de animais, pela deficiência parcial ou total de água e forragem. A palma-forrageira tem sido um recurso utilizado pelos criadores na tentativa de amenizar as dificuldades alimentares dos animais nas secas prolongadas. Essa planta xerófila apresenta adaptação às condições adversas do semi-árido, dada a sua fisiologia caracterizada pelo processo fotossintético denominado Metabolismo Ácido das Crassuláceas (CAM). As plantas que assimilam $\mathrm{CO}_{2}$ através do sistema CAM, devido às restrições na disponibilidade de água e grande pressão ambiental, que resulta em elevada transpiração, fecham os estômatos durante o dia a fim de manter a hidratação dos tecidos (Magalhães, 1979). Segundo Fisher \& Tuner (1978), as plantas que obedecem o CAM têm uma eficiência no uso de água até 11 vezes maior do que as plantas de metabolismo $\mathrm{C}_{3}$ (gramíneas de clima temperado e leguminosas). Estes autores afirmam que a eficiência do uso de água ( $\mathrm{kg}$ de água $/ \mathrm{kg}$ de matéria seca) é de 617,300 e 50 para as plantas que têm o metabolismo fisiológico $\mathrm{C}_{3}, \mathrm{C}_{4}$ e CAM, respectivamente.

Os cactus constituem exemplo mais perfeito de máxima eficiência de adaptação e aproveitamento de água e energia em ambientes de seca, além de servirem como reservatórios de água para o metabolismo durante os períodos de seca (Hills, 1982). Estima-se existir atualmente, no Nordeste brasileiro, cerca de 400 mil hectares cultivados com essa forrageira (Santos et al., 1997). Albuquerque \& Rao (1997), estudando espaçamentos em palma forrageira cultivar Gigante, de $1,0 \mathrm{~m} \times 1,0 \mathrm{~m}$; $2,0 \mathrm{~m} \times 1,0 \mathrm{~m} ; 2,0 \mathrm{~m} \times 0,50 \mathrm{~m} ; 2,0 \mathrm{~m} \times 0,67 \mathrm{~m} \mathrm{e}$ $3,0 \mathrm{~m} \times(1,0 \mathrm{~m} \times 0,50 \mathrm{~m})$, verificaram que houve diferença de produção de forragem entre os espaçamentos estudados. Farias et al. (1989) obtiveram menores produções de matéria seca de artículos de palma, quando utilizaram o espaçamento de 7,0 m x $(1,0 \mathrm{~m} \times 0,50 \mathrm{~m})$, em relação aos espaçamentos 2,0 m x 1,0 m e 3,0 m x $(1,0 \mathrm{~m} \times$ $0,50 \mathrm{~m})$. Em trabalho realizado por Barrientos Pérez (1972), com Opuntia ficus-indica, no México, utilizando os espaçamentos de $1,0 \mathrm{~m} \times 0,25 \mathrm{~m}$ e $0,50 \mathrm{~m} \times 0,25 \mathrm{~m}$, foram obtidas produções de 58,0 e $64,8 \mathrm{t} / \mathrm{ha}$ de matéria verde (MV), respectivamente.

Com espaçamentos mais adensados, pode-se alcançar maiores produções, mas os custos de estabe- lecimento do palmal são maiores e os tratos culturais ficam mais difíceis e não permitem consorciação com outras culturas. Farias et al. (1986), estudando a consorciação de 5 mil plantas de palma com 200 mil de sorgo granífero por hectare, obtiveram produções de $2.384 \mathrm{~kg} /$ ha de matéria seca de palma por ano, além de 2.488 e $967 \mathrm{~kg} /$ ha de grãos e restolhos de sorgo, respectivamente, quando o sorgo foi cultivado no ano do plantio da palma. Os mesmos autores encontraram que o uso de eficiência da terra foi mais elevada nos sistemas consorciados que nos isolados. Além de densidades de plantio e consorciação, outro fator que afeta a produtividade da palma forrageira, é o manejo da colheita. Farias et al. (1989), estudando manejo de colheita de palma durante quatro anos, verificaram que a produção de matéria seca de artículos dessa forrageira na freqüência de quatro anos foi superior à de dois anos, quando foram conservados os artículos primários, porém não apresentou diferenças quando foram conservados os artículos secundários.

Este trabalho teve por objetivo estudar diferentes espaçamentos, e as freqüências e intensidades de corte na palma forrageira consorciada com sorgo granífero, durante um período de 12 anos, buscando elevar a produtividade do sistema.

\section{MATERIAL E MÉTODOS}

Este trabalho foi realizado na Estação Experimental de São Bento do Una, da Empresa Pernambucana de Pesquisa Agropecuária (IPA), situada na microrregião homogênea do Vale do Ipojuca, Agreste Semi-Árido de Pernambuco. As coordenadas geográficas da referida Estação são: 831'56" S e 36033'0" W e 650 m de altitude (Encarnação, 1980). O solo da área experimental é Planossolo, com a seguinte composição: $17 \mathrm{ppm}$ de P; $120 \mathrm{ppm}$ de $\mathrm{K} ; 3,15 \mathrm{meq} / 100 \mathrm{~cm}^{3}$ de $\mathrm{Ca}$, $1,5 \mathrm{meq} / 100 \mathrm{~cm}^{3}$ de $\mathrm{Mg}$, e $\mathrm{pH}$ de 5,7 . A precipitação média anual da área foi de $655 \mathrm{~mm}$, com temperatura média do ar de $23,8^{\circ} \mathrm{C}$ e umidade relativa do ar de $55 \%$. O tipo climático é DdA'a' (semi-árido megatérmico), com vegetação predominante de caatinga hipoxerófila. Os dados parciais referentes ao período experimental de 1982 a 1986 foram publicados por Farias et al. (1989). No presente trabalho, foram reunidos os resultados obtidos durante todo o período experimental, de janeiro de 1982 a dezembro de 1994. Na Tabela 1, são mostrados os dados mensais de precipitação pluvial durante o período experimental. Fo- 
ram utilizadas as cultivares de palma-forrageira Gigante, $\mathrm{e}$ de sorgo granífero IPA-7300201. O delineamento experimental foi em blocos ao acaso, com parcelas subdivididas $(28,0 \mathrm{~m} \mathrm{x} \mathrm{4,0} \mathrm{m)} \mathrm{e} \mathrm{quatro} \mathrm{repetições.} \mathrm{As} \mathrm{parcelas} \mathrm{princi-}$ pais $(28,0 \mathrm{~m} \times 16,0 \mathrm{~m})$ foram constituídas pelos espaçamentos de $2,0 \mathrm{~m} \times 1,0 \mathrm{~m} ; 3,0 \mathrm{~m} \times 1,0 \mathrm{~m} \times 0,50 \mathrm{~m} \mathrm{e}$ $7,0 \mathrm{~m} \times 1,0 \mathrm{~m} \times 0,50 \mathrm{~m}$, sendo o primeiro espaçamento em filas simples, e os dois últimos, em filas duplas.

As subparcelas foram constituídas pelo arranjo fatorial de duas freqüências e duas intensidades. As freqüências foram colheitas a cada dois anos e a cada quatro anos, enquanto as intensidades foram: conservação de todos os artículos (entrenó do caule de cactus) primários e conservação de todos os artículos secundários. O preparo do solo para o plantio da palma constou de roçada, destocamento e retirada de toda vegetação da área experimental, sendo em seguida efetuado o plantio em covas, no final do período seco. O preparo do solo, plantio anual e tratos culturais para a cultura do sorgo foram realizados a enxada, com o plantio em covas em espaçamento de $1,0 \mathrm{~m} \mathrm{x}$ $0,20 \mathrm{~m}$, colocando cinco ou sete sementes. Foram deixadas quatro plantas/cova após o desbaste.

$\mathrm{O}$ número de fileiras de sorgo foi de dois, três e sete, respectivamente, nos espaçamentos de 2,3 e $7 \mathrm{~m}$. Assim, nos espaçamentos da palma, teve-se o mesmo número de fileiras e plantas de sorgo por unidade de área, ou seja 200.000 plantas/ha. Foram realizadas adubações com $20 \mathrm{t} / \mathrm{ha}$ de estrume de curral por ocasião do plantio da palma e a cada dois anos

As colheitas do sorgo foram realizadas quando os grãos se encontravam em estádio duro, ou seja, maduro, com
$88 \%$ de matéria seca. Foram pesados os grãos e restolhos (resíduo após a colheita dos grãos), e retiradas amostras dos restolhos para determinação de matéria seca, proteína e fibra bruta.

As colheitas da palma-forrageira foram realizadas com freqüência de dois e quatro anos, e com a conservação dos artículos primários ou secundários.

Após a pesagem dos artículos, foram colhidas amostras para a pré-secagem a $65^{\circ} \mathrm{C}$, para determinação de matéria seca, proteína bruta, fibra bruta e celulose, no laboratório de Nutrição Animal do IPA, seguindo metodologia da Association of Official Agricultural Chemists (1980).

\section{RESULTADOS E DISCUSSÃO}

Os dados de produções de matéria seca e de massa verde de artículos de palma, em t/ha/ano, bem como as produções de grãos com $88 \%$ de matéria seca e de matéria seca de restolhos de sorgo, conforme os tratamentos experimentais, são apresentados na Tabela 2.

As maiores produções de artículos de palma, expressas tanto em massa verde como em matéria seca, foram obtidas no espaçamento de $2,0 \mathrm{~m} \times 1,0 \mathrm{~m}$, embora as diferenças de produções apresentadas em matéria verde não tenham sido significativas, entre os espaçamentos 2,0 m x 1,0 m e 3,0 m x 1,0 m x $0,50 \mathrm{~m}$. No espaçamento $7,0 \mathrm{~m} \times 1,0 \mathrm{~m} \times 0,50 \mathrm{~m}$

TABELA 1. Precipitação pluvial (mm) no Campo Experimental de São Bento do Una, PE, durante o período experimental, de janeiro de 1982 a dezembro de 1994.

\begin{tabular}{lrrrrrrrrrrrrr}
\hline Meses & \multicolumn{10}{c}{ Anos } \\
\cline { 2 - 13 } & 1982 & 1983 & 1984 & 1985 & 1986 & 1987 & 1988 & 1989 & 1990 & 1991 & 1992 & 1993 & 1994 \\
\hline Janeiro & 10,8 & 45,2 & 16,2 & 65,4 & 21,0 & 4,2 & 9,0 & 38,4 & 27,0 & 45,8 & 124,0 & 0,4 & 44,8 \\
Fevereiro & 45,4 & 185,3 & 0,0 & 161,3 & 46,2 & 13,2 & 36,4 & 5,4 & 27,0 & 19,0 & 154,2 & 0,0 & 91,6 \\
Março & 7,2 & 92,1 & 66,3 & 149,4 & 160,6 & 312,7 & 346,0 & 43,4 & 0,0 & 188,2 & 130,0 & 0,0 & 138,6 \\
Abril & 123,8 & 25,1 & 187,8 & 332,5 & 100,1 & 67,7 & 113,4 & 62,2 & 132,2 & 61,4 & 158,8 & 16,2 & 35,2 \\
Maio & 186,8 & 61,8 & 128,7 & 18,8 & 85,7 & 4,6 & 29,8 & 166,5 & 51,4 & 67,2 & 21,8 & 19,2 & 176,2 \\
Junho & 59,4 & 50,8 & 36,7 & 67,6 & 38,8 & 82,2 & 62,0 & 112,6 & 41,6 & 24,6 & 26,0 & 40,4 & 114,0 \\
Julho & 47,0 & 73,2 & 86,2 & 67,3 & 118,6 & 80,8 & 132,0 & 98,6 & 143,2 & 23,4 & 45,2 & 54,8 & 93,2 \\
Agosto & 59,2 & 26,0 & 67,2 & 69,5 & 33,6 & 26,2 & 27,0 & 50,2 & 23,4 & 45,0 & 15,0 & 26,0 & 26,4 \\
Setembro & 15,0 & 3,8 & 39,3 & 7,8 & 26,0 & 9,1 & 23,2 & 17,2 & 1,6 & 0,0 & 69,2 & 2,0 & 44,0 \\
Outubro & 12,2 & 8,8 & 0,0 & 54,0 & 0,0 & 3,6 & 8,8 & 35,0 & 6,0 & 3,0 & 2,0 & 63,6 & 5,6 \\
Novembro & 2,2 & 19,2 & 0,0 & 1,2 & 25,4 & 0,0 & 3,2 & 15,0 & 4,2 & 36,6 & 0,0 & 13,2 & 6,2 \\
Dezembro & 20,4 & 0,0 & 0,0 & 5,8 & 4,2 & 0,0 & 77,8 & 176,8 & 3,4 & 0,0 & 1,8 & 2,6 & 7,6 \\
\hline Total & 589,4 & 591,3 & 628,4 & 1001,0 & 660,2 & 604,3 & 868,6 & 821,3 & 461,0 & 514,2 & 748,0 & 238,4 & 783,4 \\
\hline
\end{tabular}


foram obtidas as menores produções de matéria verde e seca (Tabela 2). Santos et al. (1997), utilizando espaçamento de $1,0 \mathrm{~m} \times 0,25 \mathrm{~m}$, obtiveram produções de 240 t/ha de massa verde dois anos após o plantio. No México, Barrientos, citado por Flores Valdez \& Aguirre Rivera (1992), com populações de 40.000 plantas, encontrou produções ao redor de 400 t/ha/ano.

De maneira geral, tem-se verificado que com espaçamentos mais adensados se obtêm maiores produções, porém esse sistema de plantio requer maiores investimentos na implantação e existem dificuldades nos tratos culturais do palmal. O emprego de espaçamentos em filas duplas, mais espaçadas, pode permitir a utilização de consórcio durante toda a vida útil do palmal, favorecendo a produção de grãos e restolhos de culturas para o produtor que optar por esse sistema, possibilitando um melhor emprego da mecanização no controle das ervas daninhas. Esse sistema também facilita a colheita e transporte, podendo também contribuir para reduzir os riscos de incêndio no palmal e controlar a erosão em áreas de cultura. Margolis \& Mello Neto (1975) observaram que o cultivo da palma-forrageira em faixas, com diferentes sistemas de preparo de solo, mostrou-se mais eficiente no controle da erosão, em comparação com áreas cultivadas com algodão herbáceo, milho e mamona.

Por outro lado, a consorciação da palma com outras culturas reduz a produção dessa forrageira. Albuquerque \& Rao (1997) verificaram decréscimo na produção de palma de $24,31 \%$, quando consorciada com feijão-de-corda (Vigna unguiculata L.) e de $42,81 \%$ quando foi consorciada com sorgo (Sorghum bicolor L.). Em São Bento do Una, Farias et al. (1986) verificaram que a consorciação de 5.000 plantas de palma com 200.000 plantas/ha de sorgo granífero/ha foi a que resultou em melhor produção de grãos e restolhos de sorgo, pois apesar de conter $67 \%$ da população de sorgo e $33 \%$ da de palma, em relação ao cultivo isolado da cultura, apresentou uma produção relativa de $81 \%$ de produção de grãos e $72 \%$ de produção de matéria seca de restolhos, tendo a palma produzido $42 \%$ do seu potencial, e concluíram que a eficiência de uso da terra foi mais elevada nos sistemas consorciados do que nos isolados.

Neste trabalho, verificou-se que as produções de grãos e de matéria seca de restolhos de sorgo varia-

TABELA 2. Efeito de espaçamento, freqüência e intensidade de cortes sobre a produção de matéria verde e seca de artículos de palma e de grãos e restolhos de sorgo, em consórcio com palma forrageira ${ }^{1}$.

\begin{tabular}{|c|c|c|c|c|c|c|}
\hline $\begin{array}{l}\text { Espaçamentos } / n^{\circ} \text { de plantas } \\
\text { de palma por hectare }\end{array}$ & $\begin{array}{l}\text { Freqüências } \\
\text { de cortes } \\
\text { (anos) }\end{array}$ & $\begin{array}{c}\text { Intensidades } \\
\text { de cortes } \\
\text { (conservação } \\
\text { dos artículos) }\end{array}$ & $\begin{array}{c}\text { Produção } \\
\text { de artículos } \\
\text { (matéria verde) }\end{array}$ & $\begin{array}{c}\text { Produção } \\
\text { de artículos } \\
\text { (matéria seca) }\end{array}$ & $\begin{array}{l}\text { Produção } \\
\text { de grãos de } \\
\text { sorgo } \\
\text { (88\% M.S.) }\end{array}$ & $\begin{array}{c}\text { Produção } \\
\text { de restolhos } \\
\text { de sorgo } \\
\text { (matéria seca) }\end{array}$ \\
\hline \multirow{5}{*}{$2,0 \mathrm{~m} \times 1,0 \mathrm{~m} / 5.000$} & & & & 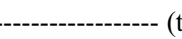 & 1a/ano) --- & \\
\hline & 2 & Primários & 43,10 & 4,20 & 1,90 & 2,21 \\
\hline & & Secundários & 64,90 & 6,41 & 1,51 & 2,10 \\
\hline & 4 & Primários & 51,31 & 5,21 & 1,60 & 2,00 \\
\hline & & Secundários & 50,51 & 5,10 & 1,61 & 2,00 \\
\hline Médias & & & $52,45 \mathrm{a}$ & $5,23 \mathrm{a}$ & $1,65 b$ & $2,07 \mathrm{~b}$ \\
\hline \multirow[t]{4}{*}{$3,0 \mathrm{~m} \times 1,0 \mathrm{~m} \times 0,50 \mathrm{~m} / 10.000$} & 2 & Primários & 41,30 & 3,82 & 1,40 & 2,31 \\
\hline & & Secundários & 47,70 & 4,51 & 1,30 & 2,10 \\
\hline & 4 & Primários & 46,30 & 4,51 & 1,32 & 2,00 \\
\hline & & Secundários & 56,49 & 5,30 & 1,31 & 2,12 \\
\hline Médias & & & $47,94 a$ & $4,53 b$ & $1,33 \mathrm{c}$ & $2,13 b$ \\
\hline \multirow[t]{4}{*}{$7,0 \mathrm{~m} \times 1,0 \mathrm{~m} \times 0,50 \mathrm{~m} / 5.000$} & 2 & Primários & 23,84 & 2,21 & 2,00 & 3,12 \\
\hline & & Secundários & 35,33 & 3,40 & 2,10 & 3,10 \\
\hline & 4 & Primários & 28,13 & 2,61 & 2,00 & 3,21 \\
\hline & & Secundários & 30,04 & 2,80 & 1,80 & 3,20 \\
\hline Médias & & & $29,33 b$ & $2,75 \mathrm{c}$ & $1,97 \mathrm{a}$ & $3,15 \mathrm{a}$ \\
\hline
\end{tabular}

${ }^{1}$ Médias seguidas de letras iguais, nas colunas, não diferem entre si $(P>0,05)$ pelo teste de Tukey. 
ram com os espaçamentos de plantio da palma. As maiores produções de grãos e de matéria seca de restolhos por unidade de área foram obtidas quando o sorgo foi consorciado com palma cultivada no espaçamento de 7,0 $\mathrm{m}$ x 1,0 $\mathrm{m}$ x 0,50 $\mathrm{m}$ (Tabela 2). Todavia, a menor produção de grão de sorgo de $1,33 \mathrm{t}$ /ha/ano, obtida no espaçamento 3,0 $\mathrm{m} \mathrm{x} \mathrm{1,0} \mathrm{m} \mathrm{x}$ $0,50 \mathrm{~m}$ e a não-diferença nas produções de matéria seca de restolhos de sorgo entre os espaçamentos de palma 2,0 $\mathrm{mx} \mathrm{1,0} \mathrm{me} \mathrm{3,0} \mathrm{m} \times 1,0 \mathrm{~m} \times 0,50 \mathrm{~m}$, sugere que este último espaçamento seja menos indicado para um sistema de consórcio palma forrageira $\mathrm{x}$ sorgo, em comparação com os outros dois espaçamentos utilizados. Como a população de sorgo foi idêntica nos três espaçamentos da palma, a menor produção de sorgo no espaçamento 3,0 $\mathrm{m}$ x 1,0 m x $0,50 \mathrm{~m}$ foi provavelmente decorrente do maior número de plantas de palma por unidade de área. Nessas condições, houve maior competição interespecífica da palma sobre o sorgo.

Por outro lado, a diferença de produção de sorgo entre os espaçamentos 7,0 m x 1,0 m x 0,50 m e 2,0 m $\mathrm{x}$ 1,0 $\mathrm{m}$ foi decorrente do arranjo espacial da palma, desde que o número de plantas de sorgo foi igual nos dois espaçamentos.

As produções de forragem de palma foram maiores $(\mathrm{P}<0,05)$ na freqüência de corte de quatro anos em relação a de dois anos, quando foram conservados os artículos primários (Tabela 3 ). No entanto, quando foram conservados os artículos secundários, não houve diferença $(\mathrm{P}>0,05)$ entre as freqüências de cortes de dois e quatro anos. A conservação dos artículos secundários - ou seja, uma menor intensidade de colheita - resultou em maiores produções de forragem apenas na freqüência de corte de dois anos, considerando-se a média das seis colheitas realizadas (Tabela 3 ).

Esse fato sugere que uma maior conservação dos artículos é importante quando se realizam colheitas mais freqüentes. Possivelmente, com a conservação dos artículos secundários se permite um maior índice de área de cladódio remanescente após o corte, o que possibilita maior eficiência fotossintética, com maior acúmulo de reservas na planta e brotação de novos artículos.

Os resultados comprovam que a palma pode ser colhida tanto na freqüência de corte de dois anos como na de quatro anos, podendo o produtor escolher a freqüência que lhe convier, de acordo com a necessidade do seu rebanho, a qual é fortemente influenciada pela duração e intensidade da seca do semi-árido. Esse resultado evidencia a necessidade de o produtor ter palmais com dois ou quatro anos de idade ou de colhido, a fim de possibilitar colheitas anuais adequadas ao sistema de manejo.

As produções de grãos de sorgo foram 1,70 t/ha na freqüência de colheita da palma de dois anos e de $1,60 \mathrm{t} /$ ha na de quatro anos, independentemente da intensidade de corte utilizada. As produções de matéria seca de restolhos de sorgo não foram afetadas $(\mathrm{P}>0,05)$ pelas freqüências e intensidades de cortes da palma forrageira (Tabela 2 ).

Os resultados da interação períodos de crescimento versus intensidade de cortes sobre a produção de forragem de palma são apresentados na Tabela 4. As produções foram maiores $(\mathrm{P}<0,05)$ quan-

TABELA 3. Efeito de freqüência e intensidade de cortes, sobre a produção de matéria verde e seca de palma forrageira ${ }^{1}$.

\begin{tabular}{|c|c|c|c|c|c|c|}
\hline \multirow{3}{*}{$\begin{array}{c}\text { Freqüências } \\
\text { de cortes } \\
\text { (anos) }\end{array}$} & \multicolumn{4}{|c|}{ Conservação de artículos } & \multicolumn{2}{|c|}{ Média } \\
\hline & \multicolumn{2}{|c|}{ Primários } & \multicolumn{2}{|c|}{ Secundários } & \multirow[t]{2}{*}{ Matéria verde } & \multirow[t]{2}{*}{ Matéria seca } \\
\hline & Matéria verde & Matéria seca & Matéria verde & Matéria seca & & \\
\hline 2 & $36,07 \mathrm{bB}$ & $3,43 \mathrm{bB}$ & $49,31 \mathrm{aA}$ & $4,76 \mathrm{aA}$ & $42,69 b$ & $4,09 \mathrm{~b}$ \\
\hline 4 & $41,90 \mathrm{bA}$ & $4,08 \mathrm{aA}$ & $45,69 \mathrm{aA}$ & $4,39 \mathrm{aA}$ & $43,79 \mathrm{~b}$ & $4,23 b$ \\
\hline Média & $38,99 \mathrm{~B}$ & $3,76 \mathrm{~B}$ & $47,50 \mathrm{~A}$ & $4,58 \mathrm{~A}$ & & \\
\hline
\end{tabular}

1 Valores seguidos de letra igual maiúscula, dentro de cada parâmetro, na linha, não diferem entre si $(\mathrm{P}>0,05)$ pelo teste de Tukey, e valores seguidos de letra igual minúscula, dentro de cada parâmetro, na coluna, não diferem entre si $(\mathrm{P}>0,05)$ pelo teste de Tukey. 
do a colheita foi realizada em plantas de palma com idade mais avançada, ou seja, as produções de forragem foram aumentando com o decorrer dos anos, em ambas as intensidade de corte. Esse fato é de grande importância prática, por se constituir num meio de conservar a palma no campo sem perda do seu valor nutritivo, o que não ocorre com outras forrageiras (Farias et al., 1989). As produções de forragem foram menores quando se conservaram os artículos secundários nas duas primeiras colheitas realizadas, enquanto nas colheitas subseqüentes, as produções foram maiores quando esses artículos foram conservados. Tais resultados podem ser explicados pela menor quantidade de artículos terciários e subseqüentes nas primeiras colheitas realizadas, enquanto nas colheitas seguintes existia maior quantidade de artículos distribuídos na planta, o que aumenta a superfície fotossintetizante, que é considerada baixa na cactácea. Santos (1992) encontrou um índice de área de cladódio de 0,508 em plantas de palma com 21 meses, em espaçamentos de 2,0 m x 1,0 m.

Os espaçamentos, freqüências e intensidades de cortes na palma forrageira não afetaram as porcentagens de matéria seca, proteína bruta e fibra bruta dos artículos da palma e dos restolhos do sorgo granífero. No tocante à palma, foram encontrados valores médios de 9,5, 4,6 e 10,9\% de matéria seca, proteína bruta e fibra bruta, respectivamente. Esses resultados estão próximos aos obtidos por Santos et al. (1990). Por outro lado, nos restolhos de sorgo foram encontrados os valores de $34,8,4,9$ e $25,8 \%$ para os mesmos parâmetros estudados, respectivamente (Tabela 5).

TABELA 4. Efeitos dos períodos de crescimento e intensidades de cortes, sobre as produções de matéria verde e seca de palma forrageira ${ }^{1}$.

\begin{tabular}{|c|c|c|c|c|c|c|}
\hline \multirow{3}{*}{$\begin{array}{l}\text { Período } \\
\text { de crescimento } \\
\text { (anos) }\end{array}$} & \multicolumn{4}{|c|}{ Conservação de artículos } & \multicolumn{2}{|c|}{ Média } \\
\hline & \multicolumn{2}{|c|}{ Primários } & \multicolumn{2}{|c|}{ Secundários } & \multirow[t]{2}{*}{ Matéria verde } & \multirow[t]{2}{*}{ Matéria seca } \\
\hline & Matéria verde & Matéria seca & Matéria verde & Matéria seca & & \\
\hline $1982-1986$ & $24,65 \mathrm{cA}$ & $2,23 \mathrm{bA}$ & $19,58 \mathrm{cB}$ & $1,72 \mathrm{cB}$ & $22,11 \mathrm{c}$ & $1,97 \mathrm{c}$ \\
\hline $1986-1990$ & $39,11 \mathrm{aB}$ & $4,19 \mathrm{aB}$ & $48,79 \mathrm{bA}$ & $5,35 \mathrm{bA}$ & $43,95 b$ & $4,77 b$ \\
\hline $1990-1994$ & $53,19 \mathrm{aB}$ & $4,86 \mathrm{aB}$ & $74,14 \mathrm{aA}$ & $6,66 \mathrm{bA}$ & $63,66 \mathrm{a}$ & $5,76 \mathrm{a}$ \\
\hline Média & $38,98 \mathrm{~B}$ & $3,76 \mathrm{~B}$ & $47,50 \mathrm{~A}$ & $4,58 \mathrm{~A}$ & & \\
\hline
\end{tabular}

TABELA 5. Efeito de espaçamento, freqüência e intensidade de cortes na cultura da palma forrageira, em consórcio com sorgo granífero, sobre as porcentagens de matéria seca (MS), proteína bruta (PB), fibra bruta (FB) e celulose na matéria seca ${ }^{1}$.

\begin{tabular}{|c|c|c|c|c|c|c|c|c|}
\hline \multirow[t]{2}{*}{ Parâmetros } & \multicolumn{4}{|c|}{ Artículos de palma } & \multicolumn{4}{|c|}{ Restolhos de sorgo } \\
\hline & MS & PB & FB & Celulose & MS & PB & FB & Celulose \\
\hline Espaçamento $2,0 \mathrm{~m}$ x 1,0 m & $10,1 \mathrm{a}$ & $4,5 \mathrm{a}$ & $10,9 \mathrm{a}$ & $13,8 \mathrm{a}$ & 34,8 & 5,0 & 25,7 & 31,8 \\
\hline Espaçamento $3,0 \mathrm{~m} \times 1,0 \mathrm{~m} \times 0,5 \mathrm{~m}$ & $9,4 \mathrm{~b}$ & $4,5 \mathrm{a}$ & $11,3 \mathrm{a}$ & $14,2 \mathrm{a}$ & 35,0 & 4,9 & 27,1 & 32,6 \\
\hline Espaçamento $7,0 \mathrm{~m} \times 1,0 \mathrm{~m} \times 0,5 \mathrm{~m}$ & $9,1 b$ & $4,8 \mathrm{a}$ & $10,5 \mathrm{a}$ & $13,8 \mathrm{a}$ & 34,7 & 4,8 & 24,7 & 32,4 \\
\hline Freqüência de 2 anos & $9,4 b$ & $4,6 \mathrm{a}$ & $9,8 b$ & $13,3 b$ & 34,8 & 4,8 & 26,2 & 32,2 \\
\hline Freqüência de 4 anos & $9,7 \mathrm{a}$ & $4,6 \mathrm{a}$ & $11,9 \mathrm{a}$ & $14,6 \mathrm{a}$ & 34,9 & 5,0 & 25,5 & 32,3 \\
\hline Conservação dos artículos primários & $9,5 \mathrm{a}$ & $4,8 \mathrm{a}$ & $10,6 \mathrm{a}$ & $14,0 \mathrm{a}$ & 34,8 & 4,8 & 25,7 & 32,2 \\
\hline Conservação dos artículos secundários & $9,6 a$ & $4,4 b$ & $11,2 \mathrm{a}$ & $13,9 \mathrm{a}$ & 34,9 & 5,0 & 26,0 & 32,4 \\
\hline Média & 9,5 & 4,6 & 10,9 & 13,9 & 34,8 & 4,9 & 25,8 & 32,3 \\
\hline
\end{tabular}

${ }^{1}$ Valores seguidos da mesma letra, dentro de cada parâmetro, na coluna, não diferem entre si $(\mathrm{P}>0,05)$ pelo teste de Tukey. 
Os percentuais de celulose foram de $13,9 \%$ e $32,3 \%$, nos artículos de palma e de restolhos de sorgo, respectivamente. Possivelmente, esses maiores valores de celulose decorrem de diferenças nos métodos de análise de fibra e celulose.

\section{CONCLUSÕES}

1. A maior produção de artículos de palma é obtida no espaçamento $2,0 \mathrm{~m} \times 1,0 \mathrm{~m}$, e a menor, em 7,0 $\mathrm{m} \times 1,0 \mathrm{~m} \times 0,50 \mathrm{~m}$.

2. A produção de forragem de palma é maior na freqüência de corte de quatro anos, em relação à de dois anos, quando são conservados apenas os artículos primários.

3. O número de plantas e o arranjo espacial das plantas de palma influenciam a produtividade de sorgo granífero, sendo a maior produtividade no espaçamento 7,0 m x 1,0 m x 0,50 m.

5. A produção de grãos de sorgo é maior na freqüência de colheita da palma de dois anos, com a conservação apenas dos artículos primários.

6. As porcentagens de matéria seca, proteína bruta e fibra bruta dos artículos de palma e restolhos de sorgo são pouco afetadas pelos espaçamentos, freqüências e intensidades de corte da palma forrageira.

\section{REFERÊNCIAS}

ALBUQUERQUE, S.G.; RAO, M.R. Espaçamento da palma forrageira em consórcio com sorgo granífero e feijão-de-corda no Sertão de Pernambucano. Revista da Sociedade Brasileira de Zootecnia, Viçosa, v.26, n.4, p.645-650, 1997.

ASSOCIATION OF OFFICIAL AGRICULTURAL CHEMISTS (Washington, DC). Official methods of analysis. 13.ed. Washington, 1980. 1018p.

BARRIENTOS PÉREZ, F. Rendimentos del nopal (Opuntia ficus-indica) var. Copena F-1 a diversas densidades. Chapingo : Colégio de Postgraduados, 1972. Não paginado.

ENCARNAÇÃO, C.R.F. da. Observações meteorológicas e tipos climáticos das unidades e campos experimentais da Empresa IPA. Recife : IPA, 1980. 110 p.

FARIAS, I.; LIRA, M.A.; SANTOS, D.C. dos; FERNANDES, A.P.M.; FRANÇA, M.P. O consór- cio de sorgo granífero (Sorghum bicolor (L.) Moench) com a palma forrageira (Opuntia ficus-indica Mill). Caderno Ômega: Série Agronomia, Recife, v.2, p.131-145, 1986.

FARIAS, I.; LIRA, M.A.; SANTOS, D.C. dos; FERNANDES, A.P.M.; TAVARES FILHO, J.J.; SANTOS, M.V.F. dos. Efeito da freqüência e intensidade de corte em diferentes espaçamentos na cultura da palma forrageira (Opuntia ficus-indica Mill), em consórcio com sorgo granífero (Sorghum bicolor (L.) Moench) Pesquisa Agropecuária Pernambucana, Recife, v.6, p.5-11, 1989. Número especial.

FISHER, R.A.; TUNER, N.C. Plant productivity in the arid and semiarid zones. Annual Review of Plant Physiology, Palo Alto, v.29, p.277-317, 1978.

FLORES VALDEZ, C.A.; AGUIRRE RIVERA, J.R. EI nopal como forrage. Chapingo : Universidad Autónoma Chapingo, 1992. 77p.

HILLS, F.S. Resistência à seca e eficiência no uso da água. In: SIMPÓSIO BRASILEIRO SOBRE ALGAROBA, 1., 1982, Natal. Anais. Natal : EMPARN, 1982. p.55-89.

MAGALHÃES, A.C.N. Fotossíntese. In: FERRI, M.G. Fisiologia vegetal. São Paulo : EPU-EDUSP, 1979. 350p. p.117-166.

MARGOLIS, E.; MELLO NETO, A.V. Observações gerais sobre perdas por erosão na zona do Agreste de Pernambuco. Recife : IPA, 1975. 20p. (IPA. Boletim Técnico, 74).

SANTOS, D.C. dos. Estimativa de parâmetros em caracteres de clones da palma forrageira (Opuntia ficus-indica Mill e Nopalea cochenillifera SalmDyck). Recife : UFRPE, 1992. 119p. Tese de Mestrado.

SANTOS, D.C. dos; FARIAS, I.; LIRA, M.A.; TAVARES FILHO, J.J.; SANTOS, M.V.F. dos; ARRUDA, G.P. de. A palma forrageira (Opuntia ficus-indica Mill e Nopalea cochenillifera SalmDyck) em Pernambuco: cultivo e utilização. Recife : IPA, 1997. 23p. (IPA. Documentos, 25).

SANTOS, M.V.F. dos; LIRA, M.A.; FARIAS, I.; BURITY, H.A.; NASCIMENTO, M.M.A.; SANTOS, D.C.; TAVARES FILHO, J.J. Estudo comparativo das cultivares de palma forrageira gigante, redonda (Opuntia ficus-indica Mill) e miúda (Nopalea cochenillifera Salm-Dyck) na produção de leite. Revista da Sociedade Brasileira de Zootecnia, Viçosa, v.19, n.6, p.504-511, 1990. 